\title{
Quality of life, mental health and health beliefs in haemodialysis and peritoneal dialysis patients: Investigating differences in early and later years of current treatment
}

\author{
M Ginieri-Coccossis*1, P Theofilou ${ }^{2}$, C Synodinou ${ }^{2}$, V Tomaras ${ }^{1}$ and \\ C Soldatos*3
}

Address: ${ }^{1} 1$ st Department of Psychiatry, Medical School, University of Athens, Athens, Greece, ${ }^{2}$ Department of Psychology, Panteion University, Athens, Greece and ${ }^{3}$ Mental Health Care Unit, Evgenidion Hospital, University of Athens, Athens, Greece

Email: M Ginieri-Coccossis* - margkok@med.uoa.gr; P Theofilou - theofi@otenet.gr; C Synodinou - clarysyn@panteion.gr;

VTomaras - vtomaras@med.uoa.gr; C Soldatos* - egslelabath@hol.gr

* Corresponding authors

Published: 14 November 2008

BMC Nephrology 2008, 9:14 doi:10.1186/147|-2369-9-14

This article is available from: http://www.biomedcentral.com/l47/-2369/9//4

(C) 2008 Ginieri-Coccossis et al; licensee BioMed Central Ltd.

This is an Open Access article distributed under the terms of the Creative Commons Attribution License (http://creativecommons.org/licenses/by/2.0), which permits unrestricted use, distribution, and reproduction in any medium, provided the original work is properly cited.

\begin{abstract}
Background: The study examines differences regarding quality of life (QoL), mental health and illness beliefs between in-centre haemodialysis (HD) and continuous ambulatory peritoneal dialysis (CAPD/PD) patients. Differences are examined between patients who recently commenced treatment compared to patients on long term treatment.

Methods: 144 End-Stage Renal Disease (ESRD) patients were recruited from three treatment units, of which I35 provided full data on the variables studied. Patients consisted of: a) 77 in-centre haemodialysis (HD) and 58 continuous ambulatory peritoneal dialysis (CAPD/PD) patients, all currently being treated by dialysis for varied length of time. Patients were compared for differences after being grouped into those who recently commenced treatment ( 4 years) and those on long term treatment ( $>4$ years). Next, cases were selected as to form two equivalent groups of HD and CAPD/PD patients in terms of length of treatment and sociodemographic variables. The groups consisted of: a) $4 \mathrm{I}$ incentre haemodialysis (HD) and b) 48 continuous ambulatory peritoneal dialysis (CAPD/PD) patients, fitting the selection criteria of recent commencement of treatment and similar sociodemographic characteristics. Patient-reported assessments included: WHOQOL-BREF, GHQ-28 and the MHLC, which is a health locus of control inventory.
\end{abstract}

Results: Differences in mean scores were mainly observed in the HD patients with $>4$ years of treatment, providing lower mean scores in the QoL domains of physical health, social relationships and environment, as well as in overall mental health. Differences in CAPD/PD groups, between those in early and those in later years of treatment, were not found to be large and significant. Concerning the analysis on equivalent groups derived from selection of cases, HD patients indicated significantly lower mean scores in the QoL domain of environment and higher scores in the GHQ-28 subscales of anxiety/insomnia and severe depression, indicating more symptoms in these areas of mental health. With regards to illness beliefs, HD patients who recently commenced treatment provided higher mean scores in the dimension of internal health locus of control, while CAPD/PD patients on long term treatment indicated higher mean scores in the dimension of chance. Regarding differences in health beliefs between equivalent groups of HD and CAPD/PD patients, HD patients focused more on the dimension of internal health locus of control.

Conclusion: The results provide evidence that patients in HD treatment modality, particularly those with many years of treatment, were experiencing a more compromised QoL in comparison to CAPD/PD patients. 


\section{Background}

Populations facing chronic illness have been reported to have poorer QoL and mental health including higher levels of depression [1-3]. In this context, health services for ill-health populations including End-Stage Renal Disease (ESRD) have drawn attention to quality of life issues and promotion of mental health [4-6]. It is worth noting that ESRD is a disease with serious effects on the patients' QoL, negatively affecting their social, financial and psychological well-being $[7,8]$.

Regarding relevant research, renal patients undergoing HD or CAPD/PD treatment were found to experience QoL deficits, while the areas affected were shown to be varied $[9,10]$. Patients' health-related QoL in these two treatment modalities was reported as being comparable; however treatment-related differences were indicated in certain QoL domains for each treatment modality respectively. Findings are mixed with some studies showing that HD patients report better physical well-being, sleep and sexual relationships $[11,12]$. Such results were indicated for the first two years of dialysis and over time $[11,13,14]$. However, adverse symptoms such as nocturnal distress and inability to sleep during the nights leading up to dialysis have also been reported by HD patients [15-17]. On the other hand, compromised physical well-being in CAPD/ PD patients has been indicated in connection to lower levels of albumin and health complications, e.g. peritonitis $[13,18,19]$.

Regarding mental health, HD patients have been found to experience more depressive symptoms than PD $[17,20]$. Depression may be linked to the HD treatment modality, since the patient has to be continually connected to the haemodialysis machine during dialysis and so experience significant restrictions in independent living $[17,20]$. In addition, the rate of reported suicide in HD is higher, while a substantial number of deaths resulting from dietary violations could also be accounted for as suicide $[21,22]$.

Furthermore, HD patients are reported to face psychosocial problems, which can contribute to conflictions between themselves and their medical carers. Such findings could be attributed in part to the stressful conditions in the HD treatment modality, including frequent visits and prolonged waiting time in the dialysis unit $[17,23,24]$.

Regarding psychological dimensions in ESRD, it seems that CAPD/PD patients are better adjusted than HD. This may be due to the peritoneal treatment modality offering increased autonomy and control, flexibility in everyday life and the dietary regime, as well as fewer social restrictions [14,25-27]. PD patients have been found to report better QoL ratings in specific areas like 'perceived ability to travel', 'financial concerns', 'restriction in eating and drinking' and 'dialysis access problems' [11]. Furthermore, PD patients have indicated more positive ratings in several disease QoL domains, e.g. less kidney disease burden, and being more encouraged and satisfied with care [28].

It is recognized that regardless of the treatment method, patients suffering from ESRD have to cope with many adversities, e.g. physical symptoms, specific dietary regimes and changes in their body image, while their control over treatment cannot always be predicted $[29,30]$. Such constraints are expected to affect the patients' life and physical and social functioning, leading patients to reconsider their personal and professional goals within the context of living with a chronic illness. Subjective issues of this kind can be investigated in patient-reported health beliefs and in perceived physical, psychological and social well-being.

Although a considerable number of articles on ESRD have been published, there are a limited number of studies comparing generic domains of QoL and mental health factors, or health beliefs in HD and CAPD/PD patients. In addition, the outcomes reported from QoL studies are frequently inconclusive. The aim of the present study was to investigate a) self-reported physical, psychological, social and environmental well-being, b) mental health factors such as anxiety and depression, as well as c) illness beliefs of health locus of control in haemodialysis and peritoneal dialysis patients. Differences were examined between patients who recently commenced treatment and those on long-term treatment (early and later years of current treatment).

\section{Method \\ The sample}

A cohort of 144 end-stage renal disease patients were recruited from dialysis units within three General Hospitals located within the broader area of Athens. From this cohort, 135 patients provided full data on the variables studied, while the remaining 9 patients were excluded having missing/incomplete data, which could be probably explained by advanced age (mean age of 67.16). The cohort of 135 participants that participated in the analysis consisted of: a) 77 patients (57.0\%) undergoing in-centre haemodialysis (HD) and b) 58 patients (43.0\%) undergoing continuous ambulatory peritoneal dialysis (CAPD/ PD), (the term PD will be used for the remainder of the text). Patients within these two treatment modalities had low comorbidity and were undergoing current dialysis for a varied period of time. In this respect, participants could be categorized into four distinct groups regarding current treatment: a) HD patients who recently commenced treat- 
ment ( $<4$ years), b) HD patients on long term treatment $(>4), c)$ PD patients who recently commenced treatment ( $<4$ years) and d) PD on long term treatment $(>4)$. A cutoff period of 4 years of treatment was agreed upon by the researchers because it was considered that a period of 3-4 years is required for patient adjustment to the diagnosis and treatment of a chronic illness. The group of HD patients with greater than 4 years of treatment included participants with a higher mean length of treatment measured in years $(12.65 \pm 6.64)$ in comparison to the respective group of PD patients (5.82 \pm 1.13). Sociodemographic characteristics of these groups are presented in Table 1.

Next, in order to investigate differences between the HD and PD treatment modalities without the possible effect of length of treatment, 41 cases of HD and 48 cases of PD patients were selected from the total cohort of 135 participants according to specified criteria to formulate two equivalent groups. Selection criteria included the patient commencing dialysis treatment within a 4 year period and ensured a balanced ratio of male/female participants within the two groups. Following the selection procedure, the two groups were tested for significant differences regarding sociodemographic variables. As seen in Table 2, the groups can be considered equivalent with no statistically significant differences between them (p. > 0.05).

All participants were of Greek nationality who gave signed consent for participation in the study. They had been informed of their rights to refuse or to discontinue participating in the study according to the ethical standards of the Helsinki Declaration (1983) [31]. Ethical permission for the study was obtained from the scientific committees of the participating hospitals.

\section{Instruments}

The following measurement tools were administered to all patients:

1) The World Health Organization Quality of Life questionnaire (WHOQOL-BREF) [32]. It is a self-report inventory of generic QoL with 26 original items and 4 additional items derived from the validation of the instrument within Greek populations $[33,34]$. The items fall into four domains: a) Physical Health, b) Psychological Health, c) Social Relationships and d) Environment, while two items provide a measurement of an Overall QoL/Health facet.

Table I: Descriptive characteristics of HD and PD patients in early and later years of treatment.

\begin{tabular}{|c|c|c|c|c|}
\hline & $\begin{array}{c}H D \\
<4 \text { years of treatment } \\
N=39\end{array}$ & $\begin{array}{c}H D \\
>4 \text { years of treatment } \\
N=38\end{array}$ & $\begin{array}{c}\text { PD } \\
<4 \text { years of treatment } \\
N=41\end{array}$ & $\begin{array}{c}\text { PD } \\
>4 \text { years of treatment } \\
N=17\end{array}$ \\
\hline \multicolumn{5}{|c|}{ Age (years) } \\
\hline $21-40$ & $10(25.6 \%)$ & $5(13.1 \%)$ & $3(7.3 \%)$ & $0(0 \%)$ \\
\hline $4 I-60$ & 14 (35.8\%) & 9 (23.6\%) & $13(31.7 \%)$ & $6(35.2 \%)$ \\
\hline$>60$ & $15(38.4 \%)$ & $24(63.1 \%)$ & 25 (60.9\%) & II (64.7\%) \\
\hline Total & 39 (100.0\%) & $38(100.0 \%)$ & $4 I(100.0 \%)$ & $17(100.0 \%)$ \\
\hline Mean \pm SD & $52.95 \pm 16.66$ & $60.53 \pm 13.59$ & $62.71 \pm 13.37$ & $67.06 \pm 9.21$ \\
\hline \multicolumn{5}{|l|}{ Gender } \\
\hline Male & 29 (74.3\%) & 22 (57.8\%) & 22 (53.6\%) & 7 (4I.1\%) \\
\hline Female & $10(25.6 \%)$ & $16(42.1 \%)$ & 19 (46.3\%) & $10(58.8 \%)$ \\
\hline Total & 39 (100.0\%) & $38(100.0 \%)$ & $4 I(100.0 \%)$ & $17(100.0 \%)$ \\
\hline \multicolumn{5}{|c|}{ Marital status } \\
\hline Single & II (28.2\%) & $8(21.0 \%)$ & 5 (12.1\%) & $\mathrm{I}(5.8 \%)$ \\
\hline Married & $26(66.6 \%)$ & $26(68.4 \%)$ & 34 (82.9\%) & $13(76.4 \%)$ \\
\hline $\mathrm{D} / \mathrm{W} / \mathrm{R}^{*}$ & $2(5.1 \%)$ & $4(10.5 \%)$ & $2(4.8 \%)$ & $3(17.6 \%)$ \\
\hline Total & $39(100.0 \%)$ & $38(100.0 \%)$ & $4 I(100.0 \%)$ & $17(100.0 \%)$ \\
\hline \multicolumn{5}{|l|}{ Education } \\
\hline Elementary & 17 (43.5\%) & $2 \mathrm{I}(55.2 \%)$ & $12(29.2 \%)$ & $8(47.0 \%)$ \\
\hline Secondary & $17(43.5 \%)$ & $8(21.0 \%)$ & 20 (48.7\%) & 9 (52.9\%) \\
\hline University & $5(12.8 \%)$ & $9(23.6 \%)$ & $9(21.9 \%)$ & $0(0 \%)$ \\
\hline Total & $39(100.0 \%)$ & $38(100.0 \%)$ & $41(100.0 \%)$ & $17(100.0 \%)$ \\
\hline Mean \pm SD & $8.44 \pm 4.15$ & $8.37 \pm 5.0$ & $10.61 \pm 3.9$ & $7.76 \pm 3.5$ \\
\hline \multicolumn{5}{|c|}{ Length of treatment } \\
\hline Mean \pm SD & $2.10 \pm 1.16$ & $12.65 \pm 6.64$ & $2.17 \pm 1.13 \%$ & $5.82 \pm 1.13$ \\
\hline
\end{tabular}

$* \mathrm{D} / \mathrm{W} / \mathrm{R}=$ Divorced/Widowed $/$ Roommate 
Table 2: Characteristics of HD and PD patients selected to form equivalent groups.

\begin{tabular}{|c|c|c|c|}
\hline & $\begin{array}{c}H D \\
N=4 I(46.06 \%)\end{array}$ & $\begin{array}{c}P D \\
N=48(53.9 \%)\end{array}$ & p-value \\
\hline \multicolumn{4}{|l|}{ Age (years) } \\
\hline Mean \pm SD & $65.34 \pm 8.37$ & $64.10 \pm 10.36$ & NS \\
\hline \multicolumn{4}{|l|}{ Gender } \\
\hline Male & $21(51.30 \%)$ & $23(47.90 \%)$ & NS \\
\hline Female & $20(48.70 \%)$ & $25(52.10 \%)$ & \\
\hline Total & $41(100.0 \%)$ & $48(100.0 \%)$ & \\
\hline \multicolumn{4}{|c|}{ Marital status } \\
\hline Single & $4(9.75 \%)$ & $6(12.50 \%)$ & NS \\
\hline Married & $33(80.48 \%)$ & $38(79.20 \%)$ & \\
\hline $\mathrm{D} / \mathrm{W} / \mathrm{R}^{*}$ & $4(9.75 \%)$ & $4(8.30 \%)$ & \\
\hline Total & $4 I(100.0 \%)$ & $48(100.0 \%)$ & \\
\hline \multicolumn{4}{|l|}{ Education } \\
\hline $0-9$ years & $29(70.73 \%)$ & $26(54.16 \%)$ & NS \\
\hline$>9$ years & $12(29.27 \%)$ & $22(45.84 \%)$ & \\
\hline Total & $41(100.0 \%)$ & $48(100.0 \%)$ & \\
\hline \multicolumn{4}{|c|}{ Length of dialysis treatment (years) } \\
\hline Mean \pm SD & $4.15 \pm 2.57$ & $3.62 \pm 2.00$ & NS \\
\hline
\end{tabular}

$* \mathrm{D} / \mathrm{W} / \mathrm{R}=$ Divorced/Widowed $/$ Roommate

NS $=\mathbf{p}>0.05$

This table displays the results of the Independent-Samples T-Test demonstrating that there are no statistically significant differences between the HD and PD groups, including patients who were selected according to specified criteria of being in the initial stages of treatment and having similar socio-demographic characteristics.

The scale has demonstrated good internal consistency with Cronbach's alpha ranging from $0.67-0.81$ per domain. It is rated on a 5-point Likert scale and the range of scores is between 1-20 with higher scores indicating better QoL.

2) The General Health Questionnaire (GHQ-28) is a widely used self-report measure of general health, developed by Goldberg (1978) [35]. The questionnaire has demonstrated good psychometric properties within Greek populations (internal consistency, validity with indices of sensitivity, specificity, positive predictive value, negative predictive value and overall misclassification rate) [36]. Besides being used as a screening tool for psychiatric cases in medical settings and general practice, it may also be used to identify self-perceived differences in mental health. The 28-item version used in this study consists of four sub-scales: a) somatic symptoms, b) anxiety/insomnia, c) social dysfunction and d) severe depression. Lower scores indicate better mental health.

3) The Multidimensional Health Locus of Control (MHLC) is a self-report inventory measuring beliefs on health locus of control. It consists of 18 items, grouped into four factors representing four categories of health beliefs: a) internal health locus, b) chance, c) doctors and d) important others. The last three refer to external health locus of control
$[37,38]$. The four factors are not mutually exclusive and scores may weight in a particular direction. Higher scores in one factor indicate a stronger presence of beliefs in the specific dimension. The questionnaire has been translated into Greek and is under validation. Preliminary evidence shows that the 4 factor model of internal, chance, doctors and powerful others may fit within the data with Cronbach's alpha ranging from $0.50-0.85$ (authors' communication).

\section{Statistical Analysis}

Kolmogorov-Smirnov tests were performed in order to check whether the values of the sample would fall within a normal distribution. Next, the analyses performed aimed to:

a) Investigate differences between patients who had recently commenced treatment and those on long term treatment within the HD and PD modalities. Thus, oneWay ANOVA analysis was performed to investigate differences within patients falling into 4 categories according to treatment modality and length of treatment. Investigation of differences included QoL domains, mental health and illness beliefs with regards to health locus of control. Next, independent Samples T-tests were performed to check differences between patients who recently commenced treatment and those on long term treatment within each 
treatment modality. Also, ANCOVA analysis was performed controlling for length of treatment in the PD and HD patients.

b) Investigate differences between HD and PD patients, using two groups comprised of selected cases from the total cohort of 135 patients, equivalent for length of treatment and sociodemographic characteristics. Independent Samples T-tests were performed in order to check for significant differences in all variables investigated in the study.

\section{Results}

The values of the total cohort were found to pass the normality distribution test. Regarding differences within the four patient groups consisting of HD and PD patients who recently commenced and those on long term treatment (early/later years of treatment), One-Way ANOVA analysis was conducted. The results of this test reveal that HD patients with more than 4 years of current treatment varied significantly from the other patient groups indicating lower QoL mean scores in the WHOQOL-BREF domains of physical health, social relationships and environment (Table 3).

In addition, according to the means of the GHQ-28 subscales, the group of HD patients with less than 4 years of treatment indicated the highest level of anxiety and insomnia, while those with more than 4 years of treatment indicated the highest mean in the GHQ-28 total score, signifying poorer overall mental health (Table 3).

A series of independent samples T-tests were then performed between the groups of patients who recently commenced and those in long term treatment and for each modality separately. Significant differences were found between the groups of the patients in the HD treatment modality. Specifically, HD patients on long term treatment had significantly lower scores in the domains of physical, psychological and social well-being. On the other hand, no significant differences in QoL and mental health parameters were found between the two PD groups of patients. It should be noted that differences in length of treatment between the PD groups were not as great as between the HD groups (approximately 3.5 years and 10 years respectively) as mentioned before and seen in Table 1.

Concerning illness beliefs with regards to health locus of control, the group of HD patients who had recently commenced treatment differed significantly from patients in the other categories, indicating the highest mean scores in the dimension of internal heath locus of control (mean scores and p-values can be seen in Table 3). As for the

Table 3: WHOQOL-BREF, GHQ-28 and MHLC in HD and PD patients in early and later years of treatment.

\begin{tabular}{|c|c|c|c|c|c|}
\hline $\begin{array}{l}\text { WHOQOL-BREF } \\
\text { domains }\end{array}$ & $\begin{array}{c}\text { HD } \\
<4 \text { years of } \\
\text { treatment }(N=39) \\
M \pm S D\end{array}$ & $\begin{array}{c}\text { HD } \\
>4 \text { years of } \\
\text { treatment }(N=38) \\
M \pm S D\end{array}$ & $\begin{array}{c}\text { PD } \\
<4 \text { years of } \\
\text { treatment }(N=4 I) \\
M \pm S D\end{array}$ & $\begin{array}{c}\text { PD } \\
>4 \text { years of } \\
\text { treatment }(N=17) \\
M \pm S D\end{array}$ & p-value \\
\hline Physical & $13.86 \pm 3.16$ & $11.95 \pm 3.76$ & $13.92 \pm 2.87$ & $13.07 \pm 2.80$ & $0.03 *$ \\
\hline Psychological & $14.34 \pm 3.02$ & $12.29 \pm 3.96$ & $13.23 \pm 3.01$ & $13.64 \pm 3.35$ & NS \\
\hline Social relationships & $13.88 \pm 2.86$ & $11.77 \pm 4.05$ & $14.13 \pm 2.33$ & $13.56 \pm 2.54$ & $0.00 *$ \\
\hline Environment & $13.05 \pm 2.64$ & $12.65 \pm 2.82$ & $14.69 \pm 1.76$ & $14.05 \pm 1.82$ & $0.00 *$ \\
\hline Overall QoL/health & $3.10 \pm 0.97$ & $2.88 \pm 1.18$ & $3.16 \pm 0.79$ & $3.11 \pm 0.91$ & NS \\
\hline \multicolumn{6}{|c|}{ GHQ - 28 subscales } \\
\hline Somatic symptoms & $1.76 \pm 0.52$ & $1.94 \pm 0.54$ & $1.66 \pm 0.52$ & $\mathrm{I} .78 \pm 0.54$ & NS \\
\hline Anxiety/insomnia & $1.95 \pm 0.68$ & $1.87 \pm 0.62$ & $1.49 \pm 0.54$ & $1.49 \pm 0.72$ & $0.00 *$ \\
\hline Social dysfunction & $2.22 \pm 0.51$ & $2.35 \pm 0.43$ & $2.17 \pm 0.31$ & $2.20 \pm 0.47$ & NS \\
\hline Severe depression & $1.46 \pm 0.64$ & $1.64 \pm 0.80$ & $1.28 \pm 0.53$ & $1.32 \pm 0.63$ & NS \\
\hline Total score & $1.85 \pm 0.45$ & $1.95 \pm 0.50$ & $1.65 \pm 0.42$ & $1.80 \pm 0.48$ & $0.04 *$ \\
\hline \multicolumn{6}{|l|}{$\begin{array}{l}\text { Health Locus of } \\
\text { Control factors }\end{array}$} \\
\hline Internal locus & $27.82 \pm 6.20$ & $25.67 \pm 7.33$ & $25.10 \pm 8.03$ & $21.46 \pm 8.4 \mathrm{I}$ & $0.04 *$ \\
\hline Chance & $25.15 \pm 8.33$ & $23.59 \pm 7.63$ & $20.94 \pm 8.87$ & $28.40 \pm 7.90$ & $0.01 *$ \\
\hline Doctors & $16.23 \pm 2.42$ & $15.43 \pm 2.84$ & $17.25 \pm 1.35$ & $16.26 \pm 2.08$ & $0.00 *$ \\
\hline Important others & $12.38 \pm 4.21$ & $11.64 \pm 4.43$ & $|2.5| \pm 4.3 \mid$ & $\mathrm{II} .06 \pm 5.76$ & NS \\
\hline
\end{tabular}

$*_{p}<0.05 ; \mathrm{N}=135$.

This table displays the results of One-Way ANOVA demonstrating differences between HD and PD patients classified into the categories of patients who recently commenced treatment and patients on long term treatment. 
groups of PD patients, those with more than 4 years of treatment indicated the highest mean score in the dimension of chance. Concerning the dimension of doctors, significant differences among the four groups were indicated. So, it is observed that HD patients with more than 4 years of treatment have the lowest mean score, while PD patients who had recently commenced treatment have the highest mean score in this dimension.

In order to test for the effect of length of treatment, ANCOVA analysis was applied controlling for years of treatment in the total cohort. The effect was observed in the WHOQOL-BREF domain of environment, in the GHQ28 subscales of anxiety/insomnia and severe depression and in the dimensions of internal and doctors regarding health locus of control.

The analysis conducted up to this point reveals that the variable of length of treatment plays a significant role in the patients' quality of life. Consequently, differences between HD and PD patients were further examined using the selective criteria of less than 4 years of treatment combined with similar sociodemographic characteristics. Based on selection of cases from the total cohort, two equivalent groups were formed comprising of PD and HD patients and were tested for significant differences. Independent Samples T-test provided evidence of no significant differences in gender, age, marital status, education and length of treatment. Table 2 shows the characteristics of these groups.
Following investigation into QoL and mental health, independent samples T-tests were then performed between the two groups of patients showing statistically significant differences. Specifically, HD patients indicated significantly lower QoL scores in the environment domain of WHOQOL-BREF. Furthermore, they reported significantly higher scores in the GHQ-28 sub-scales of anxiety/ insomnia, severe depression and the total GHQ-28 score (See Table 4).

With regards to illness beliefs, a significant difference was observed with HD patients presenting higher scores in the dimension of internal health locus of control. Both groups presented a similar pattern of illness beliefs, according to which higher values were identified in the internal and chance dimensions followed by the dimensions of doctors and important others (See Table 4).

\section{Discussion}

Deterioration in quality of life is particularly evident in the HD group of patients who have been on dialysis for an extended period of time. Most quality of life domains seem to be affected, including overall mental health. After taking into consideration that QoL deficits were mostly indicated by HD patients who had been on long term treatment, it could be argued that these patients experienced significant QoL changes over time, including deterioration in physical, social and environmental well-being as well as in overall mental health. In the relevant literature, it has been suggested that health-related QoL was more

Table 4: WHOQOL-BREF, GHQ-28 and MHLC in HD and PD equivalent groups.

\begin{tabular}{|c|c|c|c|}
\hline WHOQOL-BREF domains & $\begin{array}{c}\text { HD patients }(N=4 I) \\
M \pm S D\end{array}$ & $\begin{array}{c}\text { PD patients }(N=48) \\
M \pm S D\end{array}$ & p-value \\
\hline Physical & $12.44 \pm 3.78$ & $13.46 \pm 2.78$ & NS \\
\hline Psychological & $12.91 \pm 3.51$ & $13.16 \pm 3.16$ & NS \\
\hline Social relationships & $13.06 \pm 2.89$ & $13.69 \pm 2.21$ & NS \\
\hline Environment & $12.95 \pm 2.63$ & $14.35 \pm 1.83$ & $0.00 *$ \\
\hline Overall QoL/health & $2.98 \pm 0.98$ & $3.11 \pm 0.84$ & NS \\
\hline \multicolumn{4}{|l|}{ GHQ-28 subscales } \\
\hline Somatic symptoms & $1.86 \pm 0.58$ & $1.73 \pm 0.55$ & NS \\
\hline Anxiety/insomnia & $1.87 \pm 0.69$ & $1.53 \pm 0.64$ & $0.02 *$ \\
\hline Social dysfunction & $2.36 \pm 0.55$ & $2.22 \pm 0.36$ & NS \\
\hline Severe depression & $1.65 \pm 0.88$ & $1.32 \pm 0.60$ & $0.04 *$ \\
\hline Total score & $1.93 \pm 0.57$ & $1.70 \pm 0.48$ & $0.04 *$ \\
\hline \multicolumn{4}{|c|}{ Health Locus of Control factors } \\
\hline Internal locus & $27.36 \pm 7.00$ & $23.15 \pm 8.35$ & $0.01 *$ \\
\hline Chance & $25.21 \pm 8.65$ & $23.22 \pm 9.16$ & NS \\
\hline Doctors & $16.48 \pm 2.27$ & $16.80 \pm 1.72$ & NS \\
\hline Important others & $|3.2| \pm 4.56$ & $11.80 \pm 4.77$ & NS \\
\hline
\end{tabular}

$*_{p}<0.05 ; \mathrm{N}=89$.

This table displays the results of the Independent-Samples T-Test demonstrating differences between HD and PD patients groups, both in initial stages of treatment and with similar socio-demographic characteristics. 
compromised in HD patients, which may only become evident as time on therapy increases [39].

In particular, HD patients seem to experience a higher level of adverse symptoms such as anxiety and insomnia during the initial years of treatment, which may reflect the patient's emotional burden in having to adhere to a strict treatment regimen. It is suggested that longitudinal studies using samples that can be available over time, may be useful for overcoming cross-sectional limitations and acquiring robust evidence on QoL differences between HD and PD treatment modalities over a period of time. This is an issue of increased interest as there is evidence for changes in QoL, including a more favourable effect of HD treatment on the patients' physical well being over the first year [11]. However, it not known whether this improvement is maintained.

Regarding the PD groups, differences in QoL and mental health between patients who recently commenced and those on long term treatment are not significant. However, one should take into consideration that the PD groups of this sample did not have a large difference in terms of length of treatment, as was the case with the HD groups. It is argued that quality of life differences linked to modality without taking into consideration the time factor may restrict our understanding of differences and changes in QoL over time.

Following this line of thought, QoL controlling for the effects of length of treatment was investigated (ANCOVA). Accordingly, it was observed that patients' quality of life was only affected in the environment domain, and in the anxiety/insomnia dimension of mental health. Focusing further on the differences between HD and PD patient groups, both in initial stages of treatment, it became evident that QoL deficits in these two treatment modalities were more limited.

Accordingly, HD patients reported a more compromised quality of life indicating a higher dissatisfaction with different aspects of their environment. Specifically, these patients reported experiencing various difficulties, including a more negative opinion about availability and quality of health services. Also, they reported increased dissatisfaction with their finances, opportunities for recreation, means of transportation, as well as opportunities for acquiring everyday living information and new skills. Deficits in this area of QoL may be associated with treatment, since in-center haemodialysis imposes serious restrictions on the patient's life due to dependence on the dialysis machine. Also, dissatisfaction with health services may reflect the burden experienced by these patients, including stressful conditions during the dialysis procedure, high frequency of received in-center treatment and prolonged waiting-time in the unit $[17,23,24]$. It is noted that the WHOQOL-BREF domain of environment and the facets mentioned above seem to accurately represent the dimensions, which may be seriously affected by dialysis treatment procedures.

These results correspond to previous findings showing that it is the PD patients who report better ratings in 'perceived ability to travel', 'financial concerns', and 'dialysis access' [11], indicating increased satisfaction with their health care [28].

Furthermore, focusing on differences between HD and PD equivalent groups of patients in initial stages of treatment, HD patients reported more symptoms of anxiety, sleeping problems, depression or suicidal ideation. Problems or patterns of sleep are a central issue for many disorders and they are frequently addressed for ill as well as healthy populations $[11,40]$. Regarding the comparatively higher level of suicidal thoughts reported by this category of patients, this is a finding in agreement with international literature indicating higher rates of suicidal attempts in HD patients $[21,22]$. However, findings in the relevant literature are mixed regarding physical and psychological well-being and certain studies have suggested that HD patients reported a more positive evaluation of their physical wellbeing [12].

Regarding health beliefs, HD patients indicated a greater preference for the internal dimension focusing more on their own personal control to regulate their health condition (Table 4). This may reflect a stronger need of these patients to counterbalance the imposed dependence on the dialysis procedure and the restrictive dietary regimen by exercising control over their illness. Also, it could be the case that beliefs focusing on personal control and responsibility over one's condition could indicate selfblame and depressive mood. HD patients are reported in the relevant literature to present depressive symptomatology $[17,20]$. Further investigation into these hypotheses is necessary.

With regard to PD patients, it is worth noting that patients on long term treatment indicated a higher preference for the dimension of chance on health locus of control (Table 3 ). It may be argued that as time of treatment increases, PD patients seem to change their illness beliefs and rely less on human and professional aspects regarding their medical care, instead turning to beliefs of power stemming from unpredictable external factors, like chance. This finding may be interpreted as the patients wishing to distance themselves from medical carers. If this is the case, it should be addressed appropriately by the health professionals involved in the peritoneal dialysis treatment of the participating dialysis units. 
In addition, based on the means of the groups seen in the ANOVA (Table 3), PD patients in their initial stages of treatment seem to rely more on their doctors than the patients in the other categories. This finding may reflect the need of PD patients to rely more on the help of their medical helpers for undertaking the required training in peritoneal dialysis procedures as they are entering PD treatment.

In general, HD patients appear to endorse a more stable pattern of illness beliefs over time, as these patients, both those recently commenced and those on long term treatment appear to hold a similar weighting in the dimensions of health locus of control.

It is worth noting that findings in the area of illness beliefs of control are very limited. The results of one study reported in the literature, indicated no differences between HD and PD patients' health locus of control [41]. This psychological dimension has been well examined in HD patients in relation to adherence [42]. It is necessary however to take into consideration that methodological issues may account for differential findings, one of which is the possible cultural differences between the patient samples. It is suggested that examining cross-cultural differences regarding heath beliefs and attitudes in ESRD patients may provide answers to some of these queries.

This study has demonstrated that different QoL deficits, mental health problems and illness beliefs may characterize PD and HD patients. The findings of the present study could be used in the development of health care services and in-patient management. The role of health beliefs in particular may play an important role in the course of illness and treatment outcomes and could therefore be identified as a new area for psychological intervention in people with End Stage Renal Disease $[43,44]$.

\section{Limitations}

Limitations of the study may include the lack of investigating the effect of clinical factors such as adequacy of dialysis, hemoglobin level or other clinical parameters on the patients' perceptions of quality of life and mental health. The focus of the study however, was on QoL differences and adverse symptoms in HD and PD patients who recently commenced and those on long-term treatment.

\section{Conclusion}

The main focus of the present study was to examine QoL in $\mathrm{HD}$ and $\mathrm{PD}$ patients and investigate differences between patients who recently commenced and those on long-term treatment. The results of the study provide evidence that the HD on long term of treatment had increased deficits in physical, social and environmental QoL, as well as in mental health.
Further, patients who had similar length of current treatment in the two treatment modalities, differ only with regards to their environmental well-being. Thus, in relation to differences between patients in early and later years of treatment, it appears that QoL deficits in HD patients become more extended over time, and seem to be more precisely signified by the factors in the environmental QoL domain. It may be argued that HD patients on long term dialysis appear to be more seriously compromised in their quality of life and mental health.

\section{Abbreviations}

CAPD: Continuous Ambulatory Peritoneal Dialysis; ESRD: End Stage Renal Disease; HD: Haemodialysis; GHQ: General Health Questionnaire; MHLC: Multidimensional Health Locus of Control; PD: Peritoneal Dialysis; QoL: Quality of Life; WHOQOL-BREF: World Health Organisation quality of life instrument.

\section{Competing interests}

The authors declare that they have no competing interests.

\section{Authors' contributions}

All authors have read and approved the final manuscript. MG-C: Design of study, collection of data, analysis and write-up. PT: Collection of data, analysis and first draft. CSy: Collection of data, comments on draft. VT: Changes on the final version of the manuscript, additional points included in the discussion. CSo: Comments on final draft.

\section{Acknowledgements}

The authors would like to thank the patients for their participation in the study and acknowledge the support given by the health professionals and the administration personnel of the dialysis participating units.

\section{References}

I. Nilsson J, Masud Rana AKM, Nahar Kabir Z: Social Capital and Quality of Life in Old Age. Journal of Aging and Health 2006, 18:419-34.

2. Borglin G, Jakobsson U, Edberg AK, Hallberg IR: Older people in Sweden with various degrees of present quality of life: their health, social support, everyday activities and sense of coherence. Health and Social Care in the Community 2006, 14:136-46.

3. Demura S, Sato S: Relationships between depression, lifestyle and quality of life in the community dwelling elderly: a comparison between gender and age groups. Journal of Physiological Anthropology and Applied Human Science 2003, 22:159-66.

4. Gokal R: Quality of Life. In The Textbook of Peritoneal Dialysis Edited by: Gokal R, Khanna R, Krediet RTh, Nolph E. Dordrecht: Kluwer Academic Publishers; 1994:709-36.

5. Kimmel PL, Peterson RA, Weihs KL, Simmens SJ, Boyle DH, Umana WO, Alleyne S, Cruz I, Veis JH: Aspects of quality of life in haemodialysis patients. Journal of American Society of Nephrology 1996, 6:1418-26.

6. Gokal R: Quality of life in patients undergoing renal replacement therapy. Kidney International 1993, 43:23-7.

7. Christensen A, Ehlers S: Psychological Factors in End - Stage Renal Disease: An Emerging Context for Behavioral Medicine Research. Journal of Consulting and Clinical Psychology 2002, 70:712-24.

8. Griffin KW: Comparison of quality of life in haemodialysis and peritoneal dialysis patients. In Advances in peritoneal dialysis Edited by: Khanna R. Toronto: Peritoneal Dialysis Publications; 1994: 104-08. 
9. Griva K, Newman S: Quality of life in end-stage renal disease and treatments. In Special Issues in Health Psychology Edited by: Anagnostopoulos F, Karademas E. A Greek Perspective. Athens: Livani; 2007:97-I30.

10. Deniston OL, Carpentier-Alting P, Kneisley J, Hawthorne VM, Port FK: Assessment of quality of life in end-stage renal disease. Health Services Research 1989, 24:555-78.

II. Wu AW, Fink NE, Marsh-Manzi JV, Meyer KB, Finkelstein FO, Chapman MM, Powe NR: Changes in quality of life during haemodialysis and peritoneal dialysis treatment: Generic and disease specific measures. Journal of American Society of Nephrology 2004, 15:743-53.

12. Diaz-Buxo JA, Lowrie EG, Lew NL, Zhang H, Lazarus JM: Quality-oflife evaluation using Short Form 36: Comparison in haemodialysis and peritoneal dialysis patients. American Journal of Kidney Diseases 2000, 35:293-300.

13. Mittal SK, Ahern L, Flaster E, Mittal V, Maesaka J, Fishbane S: Selfassessed quality of life in peritoneal dialysis patients. American Journal of Nephrology 2001, 21:215-20.

14. Merkus MP, Jager KJ, Dekker FW, Boeschoten EW, Stevens P, Krediet RT, (The NECOSAD Study Group): Quality of life in patients on chronic dialysis: Self-assessment 3 months after the start of treatment. American Journal of Kidney Diseases 1997. 29:584-92.

15. Bradley $\mathrm{C}, \mathrm{McGee} \mathrm{H}$ : Improving quality of life in renal failure: ways forward. In Quality of life following renal failure Edited by: $H$ McGee, C Bradley. Chur: Harwood Academic Publishers; 1994:275-300.

16. Hooper G: Psychological care of patients in the renal unit. In Quality of life following renal failure Edited by: $\mathrm{H}$ McGee, C Bradley. Chur: Harwood Academic Publishers; 1994:181-96.

17. Oikonomidou G, Zlatanos D, Vayopoulos $H$, Hatzidimitriou $H$ : Depression in patients with chronic renal failure. Dialysis Living 2005, 14:22-32. (in Greek)

18. Oo TN, Roberts TL, Colling AJ: A comparison of peritonitis rates from the United States Renal Data System data-base: CAPD versus continuous cycling peritoneal dialysis patients. American Journal of Kidney Diseases 2005, 45:372-80.

19. Arnold R, Ranchor AV, Sanderman R, Kempen GIJM, Ormel J, Suurmeijer TPBM: The relative contribution of domains of quality of life to overall quality of life for different chronic diseases. Quality of Life Research 2004, 13:883-96.

20. Yucedal C, Olmez N, Gezen G, Celik F, Altindag A, Yilmaz ME, Kara $\mathrm{IH}$ : Depression in renal dialysis patients. European Dialysis and Transplant Nurses Association-European Renal Care Association Journal 2003, 3:160-4.

21. Gokal R: Health-related quality of life in end stage renal failure. Greek Nephrology 2002, I 4: 170-3.

22. Daugirdas J, Todd S: Handbook of Dialysis Toronto: Little Brown; 1988.

23. Gokcakan Z: The effectiveness of psychological counselling for long-term haemodialysis patients. Dialysis Transplantation 1991, 20:26-9.

24. Kennedy SH, Craven JL, Rodin GM: Major depression in renal dialysis patients: an open trial of antidepressant therapy. $J$ Clin Psychiatry 1989, 50:20-8

25. Wuerth DB, Finkelstein SH, Schwetz O, Kliger AS, Finkelstein FO: Patients' descriptions of specific factors leading to modality selection of chronic peritoneal dialysis or haemodilysis. Peritoneal Dialysis International 2002, 22:184-90.

26. Cameron JL, Whiteside C, Katz J, Devins GM: Differences in quality of life across renal replacement therapies: A meta-analytic comparison. American Journal of Kidney Diseases 2000, 35:29-37.

27. Wight JP, Edwards L, Brazier J, Walters S, Payne JN, Brown CB: The SF-36 as an outcome measure of services for end-stage renal failure. Quality in Health Care 1998, 7:209-2I.

28. Kutner NG, Zhang R, Barnhart $\mathrm{H}$, Collins AJ: Health status and quality of life reported by incident patients after I year on haemodialysis or peritoneal dialysis. Nephrology Dialysis Transplantation 2005, 20:2159-67.

29. Mavromates P: Physical activity and Chronic Renal Failure. Dialysis Living 2005, 13:22-38. (in Greek)

30. Zirogiannis P, Dombros N, Agraphiotis A, Tsakiris D: Quality of life of patients. $2^{\circ}$ Symposium of Peritoneal Dialysis. Athens 1995.
31. World Medical Association Declaration of Helsinki: Ethical Principles for Medical Research Involving Human Subjects. 35th WMA General Assembly. Venice Italy 1983.

32. WHOOOL Group: The World Health Organization's WHOQOL-BREF quality of life assessment: Psychometric properties and results of the international field trial. A report from the WHOQOL Group. Quality of Life Research 2004, I3:299-3I0.

33. Ginieri-Coccossis M, Triantafillou E, Antonopoulou V, Tomaras V, Christodoulou GN: Quality of Life Handbook in reference to WHOQOL-100. Athens: Medical Publications BHTA; 2003. (in Greek)

34. Ginieri-Coccossis M, Triantafillou E, Tomaras V, Mavreas V, Soldatos C: Psychometric properties of the World Health Organization quality of life instrument - Greek version (WHOQOLBREF). 9th Pan-Hellenic Psychiatric Congress. Athens 2006.

35. Goldberg DP: Manual of the General Health Questionnaire Windsor: NFER-Nelson; 1978.

36. Garyfallos G, Karastergiou A, Adamopoulou A, Moutzoukis C, Alagiozidoy E, Mala D: Greek version of the General Health Questionnaire: Accuracy of translation and validity. Acta Psychiatrica Scandinavica I99I, 84:37|-8.

37. Wallston BS, Wallston KA: The development and validation of the health related locus of control (HLC) scale. Journal of Consulting and Clinical Psychology 1976, 44:580-5.

38. Wallston BS, Wallston KA, DeVellis R: Development of the multidimensional health locus of control (MHLC) scale. Health Education Monographs 1978, 6:160-70.

39. Simmons RG, Abress L: Quality of life issues for end-stage renal disease patients. American Journal of Kidney Diseases 1990, I5:20I-8.

40. Soldatos CR, Allaert FA, Ohta T, Dikeos DG: How do individuals sleep around the world? Results from a single-day survey in ten countries. Sleep Medicine 2005, 6:5-13.

4I. Wolcott DL, Nissenson AR: Quality of life in chronic dialysis patients: a critical comparison of continuous ambulatory peritoneal dialysis (CAPD) and hemodialysis. American Journal of Kidney Diseases 1988, I I:402-12.

42. Christensen A, Turner CW, Smith TW: Health locus of control and depression in End Stage Renal Disease. Journal of Consulting and Clinical Psychology 199I, 59(3):419-424.

43. Rebollo P, Ortega F, Baltar JM, Diaz-Corte C, Navascues RA, Naves M, Urena A, Badia X, Alvarez-Ude F, Alvarez-Grande J: Healthrelated quality of life (HRQOL) in end stage renal disease (ESRD) patients over 65 years. Geriatric Nephrology and Urology 1998, 8:85-94.

44. Ellinikou M, Zissi A: Quality of life and chronic illnesses. Prognostic variables for the psychosocial rehabilitation of the patients with chronic illness. Medicine 2002, 82:124-3I. (in Greek)

\section{Pre-publication history}

The pre-publication history for this paper can be accessed here:

\section{http://www.biomedcentral.com/1471-2369/9/14/prepub}

Publish with BioMed Central and every scientist can read your work free of charge

"BioMed Central will be the most significant development for disseminating the results of biomedical research in our lifetime. "

Sir Paul Nurse, Cancer Research UK

Your research papers will be:

- available free of charge to the entire biomedical community

- peer reviewed and published immediately upon acceptance

- cited in PubMed and archived on PubMed Central

- yours - you keep the copyright 